\title{
SUBJETIVIDADES Y AGENCIAS QUE EMERGEN EN LA PERIFERIA URBANA: \\ Reflexiones sobre un barrio de Valencia
}

\author{
Albert MONCUSÍ FERRÉ \\ Universitat de València \\ Albert.Moncusi@uv.es
}

\section{SUBJECTIVES AND AGENCIES EMERGING IN URBAN PERIPHERY: Reflections on a district of Valencia}

Resumen: Els Orriols es un barrio popular de Valencia reconocido por su carácter multicultural, donde se está produciendo una movilización que trata de redefinir su imagen y contrarrestar aspectos que afectan negativamente a las condiciones de vida de sus vecinos y vecinas. Este texto se acerca al caso concreto de ese barrio y esa movilización para subrayar la pertinencia y potencial de la etnografía en contextos urbanos, en especial a la hora de aprehender la emergencia de subjetividades y formas de agencia, en procesos comunitarios. La etnografía en curso pone encima de la mesa manifestaciones de subjetividades y vías de agencia como son la evocación de la memoria, la expresión de temor o miedo, proyectos de futuro, expresiones de igualación y ritualización de la comunidad barrial.

Abstract: Els Orriols is a popular neighbourhood of Valencia. It is recognised by his multicultural character. There has been a mobilisation of citizens treating to redefine the image of the neighbourhood and to counter some problems that affect negatively the conditions of life there. The aim of this is to approaches to the concrete case of this neighbourhood and that mobilisation to underline the relevance and potential of the ethnography in urban contexts. The author also states the role of ethnography to apprehend the emergency of subjectivities and forms of agency, in community processes. The ethnography in course on Els Orriols shows demonstrations of subjectivities and roads of agency like evocation of the memory, expressions of fear, projects of future, essays to make all neighbours equal, discovery of possibility of agency and ritualization of urban community.

Palabras clave: Etnografía Urbana, Barrio, Subjetividades, Agencias, Centralidad Inmigrante, Inmigración Extranjera, Valencia

Urban Etnography, Neigbourhood, Subjetivities, Agencies, Immigrant Centrality, Foreign Migration, Valencia 


\section{Introducción ${ }^{1}$}

Els Orriols es un barrio ubicado en la periferia norte de Valencia. Es un antiguo pueblo anexionado a la ciudad en 1882 que experimentó cierto crecimiento urbano a mediados del siglo XX, cuando acogió a numerosos migrantes de otras zonas de España que llegaron para trabajar en la ciudad. La migración se ha hecho notar en el barrio, de nuevo, a principios del siglo XXI. Es el barrio de la ciudad que concentra la mayor población extranjera $(22,54 \%)$ y de origen extranjero $(27,7 \%)$. Se trata de un dato en descenso (en 2009 se llegó los máximos eran 31,2 y $32,8 \%$, respectivamente). La presencia de extranjeros en el barrio llamó la atención de la Administración local hace años para proponer algún tipo de intervención comunitaria y ello supuso mi primer contacto con el barrio. Después de un paréntesis, retomé hace un tiempo las reflexiones sobre Els Orriols y este trabajo forma parte del progresivo encuentro con los procesos y situaciones que allí están teniendo lugar. En el año 2012 realicé allí diez entrevistas a vecinos/as del barrio y a miembros de ONG y asociaciones que actúan en él. Más tarde, he estado participando en asambleas barriales que constituyen una importante respuesta comunitaria a unas condiciones de vida que si durante años han sido difíciles, se han visto agravadas en tiempo reciente. La participación social de vecinos/as en ese contexto supone una vía para que emerjan formas de agencia. Esta vía de acceso a la realidad comunitaria es de gran importancia, en lo que es una práctica que abre la puerta a resaltar la centralidad de la etnografía para aprehender procesos comunitarios en contextos urbanos. Por eso el primer apartado de este artículo versara sobre la centralidad de la metodología etnográfica. En un segundo apartado, abordaremos los conceptos de agencia y subjetividad, para plantear un marco interpretativo que permita dar cuenta de algunas situaciones que se producen en Els Orriols y, en especial, de la emergencia de algunos discursos y prácticas. El barrio como realidad comunitaria y la periferia como condición y nos ocuparán en una tercera parada y cuarta paradas, respectivamente. La cuestión aquí será a qué nos referimos por esas dos condiciones y, sobre todo, el papel que tienen los propios sujetos en la construcción de un barrio y de un cierto sentido de comunidad. Cerrará el texto una aproximación a algunas situaciones de marginalidad y la emergencia de subjetividades que redefinir las situaciones y producir cierta centralidad en Els Orriols.

\section{La ciudad, escenario de encuentros etnográficos}

La ciudad ha sido objeto y campo de estudio de las Ciencias Sociales desde hace mucho, pero en los últimos cuarenta años observamos una disyuntiva en la que la Antropología ha ocupado su lugar. Durante este tiempo la reestructuración del capitalismo y la globalización han supuesto la necesidad de optar por interrogarse sobre la ciudad desde un punto de vista convencional o crítico. Cuando se opta por lo primero, se incide en un enfoque funcionalista que reifica el orden económico y social de la ciudad mientras, en el segundo, se intenta poner al descubierto un "orden naturalizado de edificios y gente" y el modelo que lo conforma en base a "marcas de injusticia, disparidades y formas reificadas de poder y desigualdad" (Keith, 2009: 552). En el enfoque antropológico de la ciudad es fundamental la interrogación sobre cuestiones como la impronta cultural de la globalización en la configuración de las ciudades y en la vida de sus habitantes o la extensión del proceso de urbanización y sus consecuencias (Signorelli, 1999; Cucó, 2004). En este sentido, la mirada de la antropología

\footnotetext{
1 Este trabajo es parte del resultado del proyecto I+D "Convivencia y Barrios Multiculturales: Conflicto y Cohesión Social en una España en crisis" (CSO2014-54487-R) dirigido por la Dra. Pilar Monreal y de sendas estancias en el Laboratoire d'Anthropologie Urbaine y en el COMPAS, gracias a becas de la UVEG y a la acogida de Ben Gidley y Ane Raulin. Agradezco la colaboración en la investigación, de los/as vecinos/as de Els Orriols y, en particular, del proyecto Orriols Convive.
} 
hacia la ciudad como producto histórico-cultural y/o como contexto aporta un conocimiento eminentemente crítico, aunque su aplicación no ha resultado ni resulta sencilla.

En buena medida las complicaciones de nuestro enfoque en contexto urbano provienen de la propia definición histórica de la disciplina. Los primeros antropólogos empezaron a andar estudiando la alteridad y, al poco tiempo, comenzaron a hacerlo fijando su atención en pequeñas comunidades con cuyos miembros compartían pacientemente su tiempo en el ejercicio del trabajo de campo etnográfico. El desarrollo de la llamada "antropología en casa", desde la segunda mitad del siglo XX, ha supuesto en algunos casos la necesidad de enfocar la propia sociedad de los antropólogos aplicando un extrañamiento basado en la comparación y la búsqueda de contextos comunitarios en los que desarrollar la actividad etnográfica (Peirano, 1998). El trabajo de campo se ha desplazado a entornos más cercanos. Entre ellos se encuentra el barrio, delimitado por la distancia étnica y la pobreza como elementos exotizantes. Acudir al barrio ha constituido durante decenios una forma de mantener en casa la ilusión monográfica que la Antropología había construido originalmente en los "pueblos primitivos", como comunidades delimitadas física y socialmente y representaciones de la alteridad (Agier, 1995). Esa etnografía en casa puede resultar "etnográficamente impura y analíticamente poco parsimoniosa" (Cruces, 2003: 175), al desarrollarse en un contacto a menudo intermitente y en ocasiones breve y en un contexto difícil de delimitar, en la práctica. La explicación contextualizada en términos redes e interacciones sociales, categorías locales y trayectorias vitales es fundamental para superar las limitaciones de una visión reificadora y exotizante de lo urbano (Agier, 1995). Por otra parte, la etnografía tiene la ventaja de invitar a un permanente esfuerzo por definir epistemológicamente la propia posición, delimitar contextos difícilmente definibles y lidiar con las diferentes lógicas de los agentes (Cruces, 2003). La mirada del antropólogo sobre la ciudad tiene un alcance microsocial y está basada en comparaciones, reflexiones desde situaciones específicas y análisis metafóricos y/o metonímicos en los que se tienen en cuenta las aportaciones de otras disciplinas (Agier, 1996). Esa mirada se construye inductivamente desde la observación de prácticas e interacciones, teniendo en cuenta las diferentes perspectivas de distintos sujetos en su vida cotidiana y, en ocasiones, también en su propia colaboración con la investigación (Gidley, 2013).

La etnografía sigue manteniendo un componente experiencial basado en el largo contacto personal y negociaciones con personas, aprendizaje cultural y "reordenación de la propia intimidad y de la vida cotidiana" con un viaje constante "entre proximidad y distancia, empatía y extrañamiento, observación y participación" (Cruces, 2003). En el contexto urbano, la etnografía permite construir un triple descentramiento que posibilita aprehender la emergencia de sujetos, en cada situación concreta observada. Primero, un descentramiento cultural que llega al rehuir lecturas universalistas, segundo, un descentramiento epistemológico y situacional al observar desde las fronteras simbólicas y, en tercer lugar, un descentramiento político resultado de fijarse en situaciones de cambio o conflicto en las que los sujetos muestran su agencia (Agier, 2012). La mejor manera de dar cuenta de la emergencia de subjetividades en el barrio como contexto es aplicar esta mirada etnográfica, con toda su riqueza y complejidad.

\section{Agencias y subjetividades}

Para comprender la realidad urbana desde la antropología, resulta fundamental definir dos conceptos como son el de agencia y el de subjetividad y aplicarlos a la comprensión de la interacción cotidiana y de dinámicas de movilización social y diversificación cultural que visibilizan cambios y conflictos urbanos (Cucó, 2004): movimientos y fenómenos de resistencia ante procesos de renovación urbana y mercantilización; pugnas por mantener la identidad barrial; movilizaciones por el acceso a recursos sociales o vivienda; y esfuerzos 
por reclamar los derechos de ciudadanos que ocupan un lugar marginal en el escenario urbano. Por lo que se refiere al concepto de agencia, lo podemos considerar, con Sewell (2006[1992]), como la capacidad individual de realizar acciones a partir de cierto control sobre las relaciones sociales, desarrollada con otros sujetos, a partir de una posición estructural interiorizada subjetivamente en forma de recursos y conocimientos. La competencia más elemental que conlleva la agencia es la de incidir en la interacción cotidiana, cara a cara. La agencia supone una capacidad de actuar que se desarrolla espacialmente, en la medida en que todo espacio está construido por prácticas y relaciones (De Certeau, 1984). El espacio es una realidad transitiva, en permanente construcción, vinculada a sujetos que producen su sentido con sus interacciones y tránsitos. Si la capacidad de agencia de los sujetos radica precisamente en el espacio, con todas sus posibilidades (Corsín, 2003), como veremos después, el barrio resulta un contexto importante no solo por las vinculaciones sociales que suscita, sino también por algunos rasgos estructurales de carácter socioeconómico. Por otra parte, las relaciones cara a cara y las redes relacionales que incluyen, entre otros, a vecinos, resultan un factor fundamental para la agencia.

Por lo que se refiere al concepto de subjetividad, la entiendo en el sentido propuesto por Sherry Ortner (2006). Es decir: "el conjunto de modos de percepción, afecto, pensamiento, deseo y temor que anima los sujetos a actuar" y también "las formaciones sociales y culturales que modelan, organizan y provocan esos modos de afecto, pensamiento y demás" (2006:107). En este sentido, la subjetividad es acción o práctica en potencia y supone la generación constante de sentido. Por lo tanto, podemos entender la subjetividad como la creación de sentido, a partir de cierto marco cultural pero también de la interacción social que supone una praxis que incorpora y contribuye a configurar elementos discursivos y acciones de otros en sus esfuerzos por producir sentido mediante discursos o prácticas (De la Garza, 2000).

Las relaciones de poder se encuentran entre aquellas condiciones que Ortner considera más pueden potenciar esta agencia subjetiva. No en vano la subjetividad puede emerger de proyectos políticos como los vinculados a movimientos de resistencia o construcción de identidades étnicas. Hall (1997) lo formuló muy bien para estas últimas, cuando las relacionó "con el proceso de devenir y no de ser" y sostuvo que "las identidades son, por así decirlo, las posiciones que el sujeto está obligado a tomar, a la vez que siempre «sabe» (...) que son representaciones, que la representación siempre se construye a través de una «falta», una división, desde el lugar del Otro, y por eso nunca puede ser adecuada - idéntica - a los procesos subjetivos investidos en ellas" (Hall, 2003:20-21). Desde los estudios culturales se ha insistido en que las subjetividades se construyen a partir de la posición que ocupan los sujetos (Aquino, 2012). Todo ello ubica el surgimiento o emergencia de subjetividades en contextos en los que es preciso dotar de sentido a la realidad. Distintas subjetividades se encuentran cuando se requiere explicar algo o cuando se comparte una experiencia. Podemos atisbar cierta analogía entre esta búsqueda de sentido y la que se realiza en las religiones, por cuanto éstas, según Geertz (1995[1973]), suponen "un mayor flujo de símbolos de diagnóstico" ante la necesidad de comprender el mundo. Así, el esfuerzo del ser humano por dotar de sentido a la realidad enfatizaría la necesidad de expresar y compartir explicaciones y diagnósticos, en situaciones de conflicto.

La Antropología permite aprehender subjetividades entendidas como un conjunto de estados y emociones en las que se manifiesta lo social; subjetividades que emergen "en situación". La cuestión es reflejar las condiciones en las que irrumpe un sujeto en cierto momento y cierto lugar. Son ejemplo de ello momentos en los que alguien "toma la palabra". La emergencia de sujetos supone un distanciamiento de identidades o posiciones asignadas como la de inmigrante, extranjero o parado y el posible paso de una condición subalterna y de sufrimiento a una situación de protagonismo (Agier, 2012). Los objetos, el hogar, las fotografías y las reacciones emotivas que surgen ante esos elementos o en la conversación 
con otros, pueden ser observadas como manifestaciones de subjetividades y que podemos observar como "categorías prácticas"; es decir, desarrolladas por los actores sociales durante acciones (Semprini, 1994). Las situaciones, pues, son fundamentales para aprehender esas subjetividades. La ciudad ofrece numerosos contextos situacionales en los que explorar la emergencia de subjetividades. Agier (2009) propone una clasificación de situaciones que permite imaginar el abanico que representan, a partir de cuatro categorías: ordinarias; extraordinarias u ocasionales; de paso; y rituales. En todas ellas los actores se van encontrando poniendo de manifiesto la existencia de redes relacionales y una distinta orientación, en su relación como individuos, hacia el espacio (paseos, trayectos...) o hacia la interacción con otros (socialidad).

Cuando se trata de contextos marcadamente multiculturales, en esos encuentros los sujetos van definiendo su propia realidad de forma compartida, lo que puede incluir manifestar interpretaciones subjetivas sobre uno mismo o sobre los demás que pueden partir de prejuicios étnicos o raciales. Ahí puede producirse una valorización positiva como sujeto a partir de una identificación, en un sentido histórico, proyectivo y/o vivido o, por el contrario, una identificación negativa como estigmatización, a menudo alimentada por relaciones exógenas de dominación (Blassand, 1992). El esfuerzo por construir una imagen positiva que contrarreste la estigmatización es tanto mayor cuanto más participan de él los propios sujetos afectados (Morin y Rocheford, 1998). Como veremos enseguida, el barrio como contexto y la periferia y la marginalidad como condición están igualmente vinculados a construcciones subjetivas como reacción ante una particular valoración de esa condición.

\section{Construcciones de barrio}

Desde la Escuela de Chicago, el concepto de comunidad se ha aplicado a ciudades pensando en la conjunción de relaciones interpersonales, proximidad territorial a partir de la residencia y sentimientos y actividades de solidaridad. Este concepto se ha acabado identificando con el de barrio en buena medida por la territorialidad del trabajo de los investigadores, por su preocupación sobre la relación entre la ciudad y dinámicas de individualización y atomización y por la definición organizacional y cartográfica efectuada desde la Administración con medidas de gestión e intervención (Wellman, 1999; Gravano, 2005). En realidad, no es fácil distinguir analíticamente entre barrio y comunidad. Tal como sugiere Cucó (2004), el enfoque relacional acaba siendo el más útil para rehuir la reificación que puede representar asumir apriorísticamente la existencia de comunidades. En este sentido, el valor analítico de la noción de comunidad en contextos urbanos se puede aplicar, como ha planteado Wellman $(1979 ; 1999)$ a redes comunitarias como conjuntos de lazos y relaciones que se ramifican más allá del vecindario, con la separación entre residencia, lugar de trabajo y grupos de parentesco. Las nuevas tecnologías de la información han supuesto una expansión de estas relaciones al espacio virtual, pero las interacciones cara a cara siguen siendo garante de seguridad doméstica, control de espacios públicos y obtención inmediata de productos y servicios de primera necesidad (Wellman, 1999). En el barrio se encuentran también estas relaciones, pero tiene particularidades con respecto a otras formaciones sociales. Éstas radican en su especificidad como contexto territorial; su delimitación, el papel fundamental de la proximidad física en la vida social y la particular combinación de unidad social, física y experiencial (Chaskin, 1997).

El barrio se construye en esas prácticas de proximidad y, de acuerdo con Marin y Rochefort (1998), lo hace como espacio vivido, con percepciones y valoraciones sobre una delimitación territorial y todo aquello que contiene como aspectos materiales pero también de imágenes. Esa dimensión subjetiva se establece por cierta proximidad y cierta rutinización cotidiana, es marco de prácticas individuales, y referente de acción colectiva ante dificultades derivadas de la propia situación socioeconómica o en respuesta a proyectos 
de renovación urbana y procesos de gentrificación. El barrio, como contexto, se construye subjetivamente día a día con la interiorización de sentimientos, emociones y también con interacciones. Tal vez la manifestación más clara de esa rutinización son los vínculos más bien superficiales (en términos de duración, frecuencia, intimidad e intensidad emocional) que se desarrollan en la calle, los comercios, la escalera o los servicios públicos. Según Haning y Lieberg (1996), ese tipo de relaciones permiten fundamentar la sensación de sentirse en casa, de seguridad y de posibilidad de obtener un apoyo práctico a diario.

En contextos de diversidad cultural, esa superficialidad relacional básica conlleva cierta normalización de la diversidad cultural incluida en lo que podemos llamar coexistencia (Giménez, 2005), convivencia pacífica pero distante (Torres, 2007) o diversidad corriente (Wessendorf, 2013). Por ejemplo, Wessendorf (2013) explica como en el londinense barrio de Hackney, la asunción cotidiana de la diversidad a menudo se corresponde con discursos públicos que enaltecen el cosmopolitismo y la mezcla cultural pero, a la vez, coexiste también con estereotipos étnicos e incluso racismo hacia grupos que se considera desean mantener particularidades. La persistencia de estas particularidades en el espacio público raramente desemboca en conflictos abiertos, sino que predomina la tolerancia hacia ellas. Esas manifestaciones son presentadas discursivamente como una amenaza a un ethos de la mezcla cultural instalado en la representación oficial del barrio ideal, pero forman parte de las intrincadas relaciones cotidianas que sostienen el barrio como realidad.

La concentración de personas de determinado origen étnico puede ser un factor en el desarrollo de dinámicas de estigmatización de determinados barrios (Wacquant, 2001). Sin embargo, el carácter central de los encuentros diarios entre vecinos, por esporádicos que sean, y el respeto por la privacidad ajena se mantienen en ese tipo de barrios (Van Eijk, 2012). Varios autores sugieren algunos de los elementos que configuran la cotidianidad del barrio, a partir de relaciones vecinales que pueden ser entre personas de distinta condición de edad, étnica o de clase o entre vecinos que comparten esas condiciones ${ }^{2}$. Un primer elemento es de referencia frecuente en estudios de sociología urbana y antropología urbana ${ }^{3}$ y consiste en esa interacción cotidiana que se produce en calles, plazas y mercados, vinculada a intercambios muy puntuales o a cruces fortuitos. A esa relación a menudo no verbal, se añaden elementos de la comunicación verbal. Por ejemplo, Milliot (2003) explica cómo chismes, pullas y promesas entre los jóvenes delimitan el mundo del barrio, al poner sobre la mesa categorías que clasifican a personas y lugares y establecer un elenco de protagonistas de la vida social. Los chismes son una forma de control social y establecen fronteras simbólicas entre grupos. Las pullas suponen una forma de actualizar continuamente la inclusión en el juego social. Por su parte, las promesas fundamentan vínculos sociales entre las personas. Los comentarios sobre personas, lugares o situaciones que acaecen en la proximidad compartida del día a día van dando forma a un mundo compartido. Esa subjetividad localizada también tiene su relación con el espacio y lo hace no sólo con las prácticas y los discursos, sino también con las emociones. Las referencias al pasado, a la memoria compartida del lugar, emergidas en reuniones grupales o en paseos por el barrio producen una vinculación emocional con el barrio. Las personas invocan en sus discursos cotidianos o en aquellos generados por entrevistas o grupos de discusión una geografía afectiva en la memoria, que en el caso de los barrios suele apelar abiertamente a una especie de pasado pre-urbano comunitario e idílico. La territorialización de esas experiencias contribuye a

2 La vinculación entre el barrio y este tipo de consideración de las relaciones de proximidad tiene una larga historia en Ciencias Sociales. Gravano (2005) ha revisado esas referencias en una obra de síntesis donde, entre otras cosas, diferencia entre planteamientos de corte subjetivista o culturalista de otros más centrados en procesos socioeconómicos. El autor considera la dimensión cultural -que llama "imaginalidad"- como un rasgo que imprime cierto carácter al enfoque antropológico de lo urbano.

3 Obras como las de Joseph (1993), Delgado (2007) o Tonnelat (2010) son ejemplo de la consideración de este tipo de interacción. 
fundamentar sentimientos de pertenencia local que, en una población muy diversa, supone incorporar la multiplicidad identitaria y la contingencia como característica constitutiva (Gidley, 2013).

Pero lo emocional no termina ahí. El barrio o algunas calles o espacios concretos puede producir temor, desconfianza, miedo o ansiedad entre los potenciales transeúntes /o residentes habituales y, en barrios atravesados por la violencia, pueda acabar conllevando una tendencia a la confinación en el ámbito doméstico (Maglioni y Elizalde, 2013). En este sentido, los temores y suspicacias configuran una cartografía urbana, en particular cuando suponen una prevención con respecto a transitar por el espacio urbano (Gidley, 2013).

Como señala Keith (2009), el miedo y la ansiedad vinculados a un espacio determinado lo construyen metonímicamente con referencias a elementos ubicados en el espacio urbano y en ocasiones lo hacen en asociación categorías étnicas o raciales y con participación directa de la policía, como mostró, por ejemplo, Stuart Hall en sus trabajos sobre barrios de negros en Gran Bretaña. De este modo criminalización y etnización o racialización van de la mano (Keith, 2009). Una visión externa sobre las zonas, propuesta por políticas y sobre todo medios de comunicación, puede producir una delimitación e identificación negativa del barrio que produzca esos temores (Gravano, 2005) y que, incluso, puede llegar a disolverlo simbólicamente, al provocar desencuentros y reducir las experiencias compartidas (García Pilán y Torres, 2013). Los discursos y prácticas de los actores pero, sobre todo, sus posibilidades de agencia están condicionadas por posiciones que en ocasiones tienen que ver tanto con la consideración del barrio en tanto periférico o marginal, como con el reconocimiento como tales, de algunos de sus habitantes por parte de las instituciones de gobierno, quienes residen en otras partes la ciudad, parte del vecindario o incluso los propios sujetos.

Para interpretar la combinación entre la etnicidad como variable y la concepción del barrio vinculado a las relaciones cotidianas de proximidad y las consecuencias de sus manifestaciones urbanas, resultan insuficientes tanto las teorías asimilacionistas que plantean el horizonte de una extensión progresiva del carácter mixto de las relaciones como de las teorías multiculturalistas que pregonan la construcción y consolidación de relaciones grupales cerradas. Por el contrario, se observa que, aunque los discursos apelen a categorías étnicas "nosotros/ellos", las prácticas relacionales contradicen la distinción con contactos e intercambios que trascienden esos supuestos límites. Como hemos mostrado en otro lugar a propósito de una región fronteriza (Moncusí, 2011), las categorías etnonacionales pueden reproducirse en la práctica y en narrativas y discursos. Sin embargo, las redes comunitarias muestran que, en la práctica, se producen agrupaciones cotidianas y vinculaciones en las que las categorías e identificaciones étnicas no son significativas (Wimmer, 2004). De este modo, las situaciones relacionales acaban teniendo un papel básico, como mostraron Mitchell (1954) y Barth (1969), en el significado y delimitación de las diferencias étnicas. La diversidad cultural es inherente a la ciudad, pero toma particular significación en barrios de centralidad inmigrante donde se visibiliza uno de los rasgos fundamentales de la ciudad:

“...ha sido históricamente el crisol del cambio económico, político y cultural precisamente porque los viejos valores y los viejos órdenes se ven perturbados por el tumulto de la vida urbana. Ello produce tanto los horrores urbanos por excelencia del populismo fanático como el potencial metropolitano de la crítica ilustrada. La ciudad se sitúa, pues, paradójicamente y ambivalente entre estas tensiones, los lugares de la ciudad que exponen las más intensas formas de intolerancia son a menudo también aquellos que demuestran el potencial de las manifestaciones más íntimas de diálogo cultural"4 (Keith, 2009: 552).

4 Traducción del inglés a cargo del autor. 


\section{Periferias y marginalidades}

Algunos barrios ocupan en el imaginario urbano una posición periférica, en el sentido de estar lejos de un centro simbólico denotado por monumentos o centros de gobierno y también del centro social marcado por el acceso a recursos sociales y económicos que connotan una condición de clase mínimamente acomodada. Bourdieu (1993) plantea que un barrio puede consagrar o degradar a sus habitantes, a medida que estos comparten bien su capital acumulado o su "común excomunión", de modo que profundizan bien en su condición de "barrio elegante" o de "barrio estigmatizado". El lugar es entendido, en este contexto, como un punto en el espacio físico, social y reificado, localizado (podría decirse que incluso posicionado) en relación con otros, a partir del capital cultural, simbólico, económico, social que comparten sus habitantes y de las representaciones de los mismos. Algunos barrios, pues, acaban siendo calificados como periféricos e incluso marginales, en términos de encontrarse en una total desposesión. Como explica Wacquant (2001), quienes viven en esos barrios son calificados de "pobres" y carecen de control sobre la representación de su propia imagen colectiva; una "desposesión simbólica" que, en términos de barrios periféricos, se traduce en estigmatización territorial asociada a atribuciones de inseguridad, delincuencia, inmigración y degradación y a discursos desde y hacia el barrio, que se refieren a él como basurero o trampa. Cabe decir que esas representaciones acaban siendo monolíticas, aunque los propios vecinos diferencian claramente zonas del barrio o incluso bloques que están mejor o peor y que algunos consideren un caso perdido sólo solucionable demoliéndolos.

La situación de marginalidad es resultado de un proceso que "consiste socialmente en la exclusión del marginado de los espacios sociales, del acceso institucionalizado a los recursos comunes o públicos", sea como opción alternativa o como única posibilidad (San Román, 1991:152). La marginalidad es el resultado estructural de ese proceso a partir de la institucionalización de la ubicación de algunos sujetos en una sociedad en el "margen de los procesos económicos y políticos oficiales" (Lomnitz, 1975). La vertiente urbana del proceso deriva de una cuestión de justicia espacial, en la ciudad, en el sentido de que un sector social ubicado en un "espacio urbano distintivo" es despojado del acceso a recursos a los que sí tienen acceso otros ciudadanos y, en particular, los que habitan otras zonas (Gravano, 2005). Wacquant (2001) ha presentado a fondo la marginalidad urbana como manifestación espacial del proceso de marginación en "barrios relegados de mala fama en los que el aislamiento y la alienación sociales se alimentan uno al otro". La creciente desigualdad, la mutación del trabajo asalariado en desempleo y precarización laboral, la crisis del estado del bienestar y la concentración y estigmatización urbanas han sido identificadas por el autor como causas sistémicas de la situación de marginalidad (identificada por él como pobreza) que experimentan habitantes de determinados barrios.

El mismo autor explicó en su día cómo residentes de La Courneuve, en el norte de París, experimentaban un aislamiento que reproducen ellos mismos con prácticas como no tomar nunca un taxi en la misma puerta de casa o advirtiendo a las propias hijas de que no salgan con chicos de allí. Esa misma imagen conlleva un trato distinto por parte de tribunales, Servicios Sociales o policía. Prácticas y discursos de diferenciación interna reducen la confianza interpersonal y la solidaridad local. Destacan el valor moral individual o familiar y la crítica a los vecinos que se apropian ilegítimamente de programas de asistencia social; un discurso crítico de devaluación de los habitantes para atribuirse valor uno mismo. Wacquant (2001) se refiere a la imposible definición de un sentido de comunidad y a la producción, por el contrario, de anomia. Para él, los jóvenes suelen ser el principal foco de preocupación en el barrio. Sin embargo, la heterogeneidad étnica es la norma, con lo que resulta erróneo comprender la realidad de esos barrios aplicando la noción de gueto.

De todos modos, la marginalidad urbana no se produce por dinámicas propias y específicas de una ciudad, sino que en parte resulta de metamorfosis y dinámicas glocales vinculadas a un modelo de ciudad, el neoliberal, que muestra las dos caras de una misma moneda: 
la espectacularización y la precarización. Valencia, como muchas otras ciudades, ha sido exponente de ello (Santamarina y Moncusí, 2013; Cucó, 2014; Santamarina, 2014). Pero, además, en el caso específico de los ciudadanos extranjeros, se hace patente que la realidad urbana se encuadra en el marco político del Estado nación y que el derecho a la ciudad tiene mucho que ver con la ciudadanía nacional. Como sugiere Keith,

"La ciudad representa una territorialización de poderes de gobernanza y organización social, pero depende de un sentido afectivo de su propia identidad (un imaginario de ciudad) y presupone la existencia de un estado más allá de sus fronteras (...). El estado moderno taxonomiza la división territorial de sus regímenes de control a través de unidades geográficas subsidiarias. Sin embargo para hacer visibles a los sujetos de su poder ese estado necesita una organización racional de la demografía y una jerarquía funcional de asentamientos que encuentra en la urbanización su lógica económica conductora" (Keith, 2009: $550)$.

Puede decirse, pues, que la marginalidad urbana tiene una particular vertiente espacial si se mira a nivel global y en relación con la cuestión de la ciudadanía y la nacionalidad. Como ha destacado Gil Araújo (2009) en virtud de una histórica jerarquización internacional de raíz colonial, con centros y periferias, persisten desigualdades entre sujetos que residen en un territorio nacional siendo considerados extranjeros o, mejor dicho, "inmigrantes". Es una periferización que se reproduce en ciudades a las que emigran esas personas llevando consigo aquella condición periférica que les convierte en potenciales marginados a ojos de los ciudadanos del centro. La situación jurídica de los inmigrantes sin papeles limita su capacidad de participación y acción política, ubicándolos en una situación marginal puesto que "las normas migratorias construyen categorías de personas y crean nuevas formas de desigualdad, pero también refuerzan las desigualdades políticas, económicas y sociales preexistentes y las divisiones que tienen, a menudo, una naturaleza basada en las relaciones de género y generacionales" (Gil Araújo, 2011: 61). En este sentido, la condición inmigrante (Toubon y Messamah, 1990).

Pero, ¿se encuentran los sujetos completamente atados al estigma de la condición inmigrante o tienen algún margen de maniobra? ¿Hasta qué punto el contexto barrial les ata todavía más a ella? ¿Existen respuestas desde la gobernanza urbana? ¿Tienen esos sujetos algún tipo de agencia? ¿En qué contextos emerge? ¿Están solos, en su condición? ¿Pueden orientarse de algún modo hacia una posición de mayor centralidad?

Como hemos apuntado ya, dada la configuración sociopolítica y socioeconómica de sociedades que se encuentran en una posición de relativa centralidad internacional en términos políticos y económicos, los inmigrantes como tales se encuentran en una situación marginal con respecto a derechos de ciudadanía. Se produce una estratificación cívica, con distintos grados, a partir de la institucionalización de la ciudadanía en condiciones de desigualdad (Lockwood, 1996) en la que los inmigrantes en situación irregular suelen ocupar la peor posición, con imposibilidad de ejercer derechos políticos y dificultades para acceder a servicios sociales (López Sala, 2006). En esas condiciones, parece complicado desarrollar formas de agencia. Por otra parte, la cuestión espacial puede suponer un plus de dificultades al producirse ciertos efectos de barrio, en el sentido de que se refuerzan las estructuras del orden social, proyectando el carácter simbólico del barrio sobre sus habitantes. La morfología (trama urbana, infraestructuras, servicios...), localización, historia e imagen del barrio dejan huella en quienes lo habitan, condicionando sus relaciones de sociabilidad. Además, ese efecto deriva también de las condiciones sociales de esos habitantes (Authier, 2006). Esta proyección de las características del barrio sobre sus moradores fue desarrollada por primera vez en Estados Unidos, en los años sesenta del siglo XX, para explicar el compor- 
tamiento de los sujetos como efecto de un contexto entendido como suerte de ecosistema o realidad socializadora. Se ha solido aplicar tanto en aquel país como, más tarde, en Europa, a barrios aquejados de situaciones de conflictividad social, violencia y pobreza. Aunque no siempre se ha hecho a partir de información precisa, ha supuesto el establecimiento de un discurso político de la mezcla social como solución tanto en Francia como en el Reino Unido (Van Ham y Manley, 2012).

Este discurso de la mezcla ha sido aplicado desde algunos gobiernos. Francia es un exponente de ello, con una larga tradición de intervención pública para la cohesión social frente a falta de alojamiento, trabajo, educación, cultura y servicios en general en barrios calificados con adjetivos que resaltan su vulnerabilidad y carencias (sensibles, frágiles, en crisis...). En este tipo de labor, se ha tenido en cuenta la proximidad reforzando relaciones de solidaridad y sociabilidad, aspectos que toman especial relevancia ante la crisis del Estado del Bienestar y las limitaciones del mercado (Morin y Rochefort, 1998). Las políticas tienen como uno de los caballos de Troya intervenciones urbanísticas que suponen la renovación del parque urbano y la atracción de clases medias a zonas populares (Bacqué, 2011). Algunas de las intervenciones suponen la instalación de equipamientos culturales que persiguen dar un significado distinto al lugar y un uso diferente al espacio (Vivant, 2007). Este tipo de acciones puntuales tratan de redefinir metonímicamente un conjunto espacial a partir de la intervención en un punto concreto (Keith, 2009), aunque pueden combinarse con apoyo económico a iniciativas de los propios vecinos con las que se intenta potenciar la cooperación entre vecinos de distinta condición social.

En barrios étnicamente heterogéneos, discursos oficiales, pero también de comerciantes y activistas apelan al espíritu comunitario de barrio y/o a la ciudadanía, sin referencias a orígenes etnonacionales concretos e incluso en ocasiones con referencias explícitas al valor de la heterogeneidad cultural y el carácter cosmopolita y abierto. Se trata de un proceso de cosmopolitización que contribuye a fundamentar formas de pertenencia local y también formas de mercantilización. La celebración de algunos carnavales o festivales ejemplifica un proceso que supone la emergencia de subjetividades cosmopolitas (Povrzanović, 2015).

Cuando estas iniciativas se desarrollan al margen de programas públicos y apelan a una triple dimensión identitaria se puede decir que refuerzan la identidad colectiva (Morin y Rochefort, 1998). Esa triple dimensión es histórica (vinculada a la memoria y el patrimonio), proyectiva (orientada a proyectos de futuro) y vivida (fundamentada en la experiencia cotidiana del territorio y el espacio) ${ }^{5}$. La participación de vecinos en situación marginal, y en particular de los migrantes en situación irregular, puede suponer la emergencia de formas de agencia. En este sentido, se puede decir que los escenarios de interacción entre personas de distintos orígenes pueden suponer la transgresión de barreras étnicas cuando suponen cierta continuidad y conllevan formas de colaboración, como sucede en el caso de los centros sociales, regeneración de espacios, proyectos artísticos, entre otros. Pueden ser fórmulas de emergencia, creación y transformación, por lo que suponen de contacto pero también por aspectos de contenido como, en el caso de proyectos de Artes Escénicas, las temáticas enfocadas en los guiones o la expresividad compartida (Amin, 2002).

Si Goffman (1970) mostró que una de las vías de respuesta a la estigmatización social es la búsqueda de apoyo mutuo más allá de un contexto familiar que se antoja incapaz de afrontar los efectos de discursos y prácticas estigmatizantes, los contextos de participación colectiva, activados en los barrios a menudo por ONG o asociaciones, pueden facilitar ese tipo de apoyo facilitando el encuentro con otras personas en similar situación y promoviendo un espacio de reconocimiento como sujetos en el que pueden hablar, ser escuchados y protagonizar iniciativas de distinto tipo. Por otra parte, como veremos para el caso de Els Orriols, la creación de ese tipo de espacios comunitarios puede ofrecer vías para la pro-

5 Morin y Rochefort (1998) proponen esta triple dimensión a partir de Bassand (1992). 
ducción de contactos y relaciones vecinales, para la producción de una imagen distinta del barrio e incluso reclamar o implementar nuevos usos para el espacio urbano o la instalación de equipamientos y servicios. Se trata de la inclusión de aquellos sujetos marginalizados por su condición de inmigrantes en iniciativas comunitaristas, que se caracterizan por cimentar la unión vecinal en la protesta contra el capital y su materialización en la construcción o destrucción de edificios o la reclamación de servicios como escuelas, centros de salud o zonas verdes. Keith (2009) ha explicado que no sería la única fórmula comunitarista, puesto que existe otra que invoca el derecho a mantener la propia identidad y controlar la presencia de personas sin hogar, antisociales o extranjeras. Obviamente, la diferencia es la inclusión o exclusión simbólica y real de sujetos marginalizados.

Según explica Amin (2002) citando un informe de la Home Office londinense, la cohesión comunitaria tiene varias dimensiones: valores comunes y cultura cívica, redes sociales y capital social (en términos de Putnam, con el papel central de la confianza social), identificación emocional con el lugar, control, orden social y tolerancia y solidaridad social e igualdad socioeconómica). La heterogeneidad cultural y social parece ajustarse difícilmente a esa propuesta y, en algunos casos, es necesario admitir que esa comunidad cohesionada no es más que una idea inalcanzable que simplemente permite abrir tendencias comunitarias en un contexto permanentemente abierto a la heterogeneidad, la diferencia y la atomización de grupos con distintas formas de cimentar su identificación local, con diferentes valores y prácticas culturales. Ante ese ideal, la principal propuesta de futuro es establecer oportunidades para que surja una subjetividad abierta a la diferencia, debate, el cuestionamiento y la mirada crítica a la propia realidad (Amin, 2002).

Si entendemos la centralidad como el contrapunto a la marginalidad, en términos de Wacquant, pobreza y riqueza indicarían esos dos extremos. Sin embargo, me interesa destacar aquí que la agencia social y la movilización pueden suponer una alternativa distinta, no específicamente económica, sino más bien política, que no tiene la capacidad inmediata de modificar la situación de marginalidad, pero puede ayudar a contrarrestar el olvido o la ocultación en tanto ciudadanos, a la que se ven expuestos sujetos como los inmigrantes sin papeles. El establecimiento de espacios vecinales donde se trabaja por una comunidad en torno a la noción de barrio puede ser entendido como una redefinición de la situación periférica o marginal de algunos de sus habitantes e incluso de la propia posición del barrio con respecto al conjunto de la ciudad.

\section{Subjetividades y nuevas centralidades en Els Orriols (Valencia)}

Els Orriols es un barrio de poco más de 16000 habitantes que puede ser definido como periférico por estar al límite de la ciudad de Valencia con otras poblaciones que se encuentran al norte de la misma pero también por ser un barrio de condición obrera. En los años sesenta fue destino de inmigración de personas desde otras zonas de España y, sobre todo, Castilla la Mancha y Andalucía que acudían a la ciudad para trabajar. El arquitecto Barona fue el responsable de la construcción de varios bloques de sencillas viviendas destinadas a alojar a esa población y a otros residentes con escasos recursos (entre ellos algunos gitanos). Esos bloques se encuentran hoy muy cerca de lo que era el centro del anterior núcleo urbano y constituyen un conjunto de pisos cuyo reducido tamaño contribuye a hacer de Orriols uno de los barrios con mayor densidad poblacional de toda la ciudad $(405,7 \mathrm{hab} / \mathrm{m} 2)$. Del antiguo pueblo quedan algunas pequeñas casas, unas pocas alquerías en la zona más septentrional y una ermita. El núcleo del barrio constituido por aquellas viviendas es conocido popularmente como "Barona" y ha ejercido cierto efecto metonímico sobre el conjunto del barrio, expandiendo una imagen de pobreza, droga y delincuencia.

En los últimos quince años el barrio ha desarrollado una importante centralidad inmigrante. Pese a haber experimentado un significativo descenso de población de origen ex- 
tranjero (un 26,2\% entre 2009 y 2014), el barrio se mantiene a la cabeza en concentración de población de ese perfil $(27,3 \%)$. Además, algunas secciones censales tienen concentraciones de un $30 \%$. Ahora bien, esa centralidad se debe también a que se encuentran allí el Centro Cultural Islámico, un templo Sikh, la Oficina de Extranjería de Delegación del Gobierno y la ONG Valencia Acoge, así como algunos comercios étnicos. A todo ello se suma la población gitana, para dotar al barrio de un marcado carácter multicultural. Además, la existencia de la Iglesia Evangélica de Barona completa la pluralidad también en el terreno religioso.

Según el Atlas de Vulnerabilidad Social en España, Els Orriols era el segundo barrio en tasa de paro juvenil en toda la ciudad, en 2001 (16,49\%), y se encontraba en cuarto lugar en percepción de la delincuencia como problema siendo, además, un barrio catalogado como vulnerable por la tasa de población analfabeta y sin estudios, tasa de paro y población en viviendas sin servicio o aseo. Desde 2006, se suma al cálculo el índice de población extranjera, estimado por entonces en el 30,6\%). Es significativa la incorporación de este dato, por cuanto puede darse el caso de barrios a los que se atribuya la condición de vulnerabilidad exclusivamente por este dato. Es el caso, de hecho, de Russafa, incluido en 2006 en el catálogo de barrios vulnerables solamente por el porcentaje de población extranjera.

Estos últimos años, el barrio ha sido fuertemente golpeado por la crisis (Torres y otros, 2015). Según declaraciones a la prensa de una secretaria judicial, era hace unos años el barrio que más desahucios experimentaba cada semana en toda la ciudad (Levante, 28/11/12). Rascanya (distrito que incluye el barrio) era el tercero en media de desempleados en 2013, con una tasa del $23,6 \%$, empeorando datos previos (en 2008 era el quinceavo, con $8,8 \%$ ). En algunas entrevistas realizadas en el barrio en 2012 se sostiene que se estarían produciendo tensiones y peleas por la falta de recursos e intervención pública y por la de personas "en riesgo de exclusión social”, como inmigrantes y gitanos. La ocupación de viviendas que han quedado vacías por los desahucios, fundamentalmente en la zona de Barona, es otra de las cuestiones que surge. Por otra parte, informes de Servicios Sociales Municipales de 2012 sugerían que había problemas derivados de falta de empleo y dificultades para pagar la propia vivienda.

La urbanización de una zona colindante con Barona, llamado Nuevo Orriols, con edificaciones viviendas modernas, de mayor tamaño, en algunos casos condominios con piscina y parque privado produce un contraste con aquella zona del barrio. A tenor de los comentarios recogidos en conversaciones informales, reuniones y entrevistas, algunos de los residentes de esa zona se desplazaron allí desde otras partes del barrio buscando una mejor vivienda. Cerca de Nuevo Orriols están el Campo del Levante U.D., el principal parque de la zona y, desde 2010, un centro comercial.

Existen notables diferencias con casos como las Banlieues francesas, en cuanto a aspectos como la concentración de extranjeros de determinado origen, la segregación geográfica con respecto al centro urbano o la inseguridad y la intervención policial. Sin embargo, se puede hablar de un barrio estigmatizado, con vivienda barata, densidad de población, condiciones socioeconómicas desfavorables, carencia de servicios y referencias en los de comunicación que no sólo se hacen eco de esos problemas, sino que realizan alguna referencia al papel de los grupos de jóvenes d origen extranjero (Moncusí y otros, 2015). La entrada en escena de la extrema derecha en el barrio, con un reparto de alimento "solo para españoles", una manifestación "por los derechos sociales" y un reparto de panfletos y proclama de consignas islamófobas, en el último año, pueden completar un panorama que puede parecer cuanto menos inquietante. Sin embargo, el barrio cuenta con un tejido social que se ha movilizado, incorporando a ONG, entidades religiosas, asociaciones de migrantes, asociaciones de vecinos, entidades de comerciantes, centros educativos, movimiento $15 \mathrm{M}$, plataforma de parados y vecinos a título individual ¿Cuáles son las subjetividades y agencia que emergen en Els Orriols? ¿En qué contextos? ¿Puede hablarse del desarrollo de 
nuevas centralidades?

Las primeras entrevistas que se realizaron el barrio, en 2007 y 2008 permitieron dar cuenta de una sensación de competencia étnica y del mantenimiento de algunos prejuicios con respecto a colectivos de extranjeros. Pude participar en algunas reuniones de una plataforma de entidades y, sobre todo ello, me aventuré a realizar algunas reflexiones. En 2012 realicé nuevas entrevistas, en un proyecto de largo plazo de comparar el barrio con otro de la ciudad (Russafa) conocido también por su centralidad inmigrante. Recientemente he realizado un paso más de carácter etnográfico, participando en asambleas, aportando propuestas e ideas y haciéndolo, en algún caso, como profesor de la universidad que puede aportar recursos de apoyo desde la institución en la que trabajo.

El contexto es el proyecto Orriols Convive, promovido por la entidad Valencia Acoge a partir de fondos europeos y que ha supuesto la creación de una plataforma vecinal instituida como asociación y de un centro comunitario en el que se realizan asambleas periódicas y varias actividades. Esa nueva situación me ha dado que pensar y en ello estoy. Los siguientes pasos deberán pasar por consultar con los propios vecinos sobre mi propio trabajo y ver si consideran que puede aportarles algo a ellos y al barrio. Lo que acabo de contar ya es la emergencia de una subjetividad: la del propio etnógrafo. Es, también, una voluntad de reconocer las subjetividades de los propios vecinos. Es decir, las emociones, afectos, imaginación, deseo, identificación, cognición, recuerdo como procesos que contribuyen a dotar de sentido al lugar. Algunas situaciones observadas en esta etapa en la que me encuentro permiten aventurar algunas posiciones subjetivas que dan forma al barrio. Se trata de reflexiones que surgen en las asambleas y en situaciones que he podido observar. Propongo un esbozo de situaciones que catalizan el surgimiento de esas posiciones o subjetividades: evocación de memoria, expresión de temor o miedo, proyectos de futuro compartido, expresiones de igualación, descubrimiento de la posibilidad de agencia y ritualización de la comunidad barrial. Vamos, pues, a cerrar esta reflexión con varias viñetas que ilustran cada una de esas subjetividades esbozadas.

\section{a) Evocación de la memoria}

En una de las entrevistas una vecina de origen español y participante de distintas asociaciones recordaba cómo le decían que era el barrio, de pequeña:

En realidad Barona es Orriols... A la gente no le gusta llamarlo Barona porque Barona era... lo peor que había en Valencia. Siempre decían "no vayas a Barona"... Mi madre no me dejaba cruzar Primado Reig porque Barona era lo peor que había... En la época de la heroína y todo esto, aquí hizo estragos, en los años setenta (Or1)

Otras situaciones se han dado en el propio proyecto, con la creación de una exposición de fotografías antiguas, de extractos de un libro sobre historia del barrio y de un ciclo de conferencias en el que, entre otras cosas, se recordaba el pasado de movilización vecinal. Se ha promovido también una ruta por el patrimonio histórico y arquitectónico vinculado que incluyó un monasterio medieval, una alquería y las casas restantes del antiguo pueblo. La visita fue también una ocasión para reivindicar la recuperación de esos elementos y entre quienes participaron en ella se encontraba el que probablemente sea nuevo alcalde de la ciudad, que acudía como jefe de filas de su partido (Compromís). La memoria, pues, puede evocar a la vez un pasado problemático en una situación como la entrevista pero suponer también la identificación con otros relatos y hitos, en contextos de carácter más público.

\section{b) Expresión de temor o miedo}

El miedo o temor apareció verbalizado en asambleas al menos tres veces. La primera, a raíz del anuncio de la organización de extrema derecha España 2000, que dijo que acudiría 
al barrio a repartir comida "sólo a españoles". Un vecino de origen senegalés expresó enfáticamente que él ese día no saldría a la calle y propuso que se advirtiera a todos los vecinos de origen extranjero que hicieran lo mismo. Habló explícitamente del miedo que le producían esa gente de extrema derecha. En cierto modo, el temor fue compartido, y hubo un debate sobre si deberían cerrarse los comercios o realizarse recorridos por las calles para garantizar la seguridad. En otra ocasión, apareció el miedo cuando una vecina procedente de algún país de la Europa del Este explicó que la presencia de policías en las calles le producía sensación de inseguridad. Finalmente, en varias ocasiones ha habido comerciantes y vecinos españoles que han expresado miedo e inseguridad en las calles o en sus establecimientos. Todo ello ha supuesto que se plantee un debate sobre la presencia y la acción policial en el barrio, pero también que se busque el apoyo y mediación desde Servicios Sociales.

\section{c) Proyectos de futuro}

Una de las iniciativas surgidas del proyecto Orriols Convive es el uso de una explanada que se encuentra delante de la ermita de San Jerónimo. Durante los dos últimos veranos se han realizado allí conciertos y sesiones de cine. Por otra parte, el pasado 18 de abril se realizó allí la jornada "Sembra Orriols", encaminada a explorar participativamente posibles nuevos usos del descampado. Entre otras cosas, se enunciaron los que se consideraban eran los principales problemas (sobre todo suciedad) y se propusieron nuevos usos, entre los que destacaron el ocio y la cultura. El tema ha sido recurrente en varias asambleas y constituye un proyecto de futuro, aunque no el único. Otra cuestión recurrente es la creación de un centro cultural que dé continuidad al proyecto.

En otros términos, en varias ocasiones se producen referencias a los barrios de Benimaclet y Russafa como ejemplos a seguir, para generar un barrio cohesionado en base a la movilización vecinal, el comercio de proximidad y, en el caso del primero de los dos barrios, el éxito en la lucha contra la extrema derecha y la promoción de la convivencia intercultural.

\section{d) Expresiones de igualación}

En primer lugar, he visto situaciones en las que alguien expresa la sensación de ser tratado de manera distinta, lo que supone por su parte la expresión de un deseo de igualación. En una de las asambleas fue lo que expresó un vecino cuando dijo que él vivía en Nuevo Orriols, en un piso de protección oficial, y que no todos allí eran "ricos". Era la respuesta a una referencia que se produce a menudo, a esa zona del barrio como rica. Otra versión, en este caso culturalista, son las expresiones de cosmopolitismo con la organización de actividades culinarias o artísticas que evocan la diversidad cultural como constitutiva del barrio y suponen un intento explícito de distinguir diferencia de desigualdad. Por último, es significativo el esfuerzo por evitar referencias discriminatorias hacia los gitanos, cuando se acordó en la segunda asamblea dejar de hablar de "gitanos" para referirse a algunas familias que producían problemas en el barrio.

\section{e) Ritualización de la comunidad barrial}

Si hay un problema que se enuncia repetidamente como el principal del barrio en las asambleas ese es la limpieza. La iniciativa más visible frente a ese problema ha sido la organización, hasta en tres ocasiones brigadas de limpieza multitudinarias. Es habitual que se desarrollen en un recorrido que evidencia la centralidad de Barona en las reivindicaciones y también la del descampado, donde en alguna ocasión han terminado y el local del proyecto, donde empiezan. Se trata de una forma de uso extraordinaria de un espacio - la calle- usada de ordinario de otro modo. Como se ha explicado en un trabajo colectivo dirigido por Delgado (2003) son prácticas mediante las cuales se ponen en estado de excepción el tiempo y el espacio, al servicio de la afirmación simbólica de un cierto espíritu comunitario alrededor de una reivindicación. Ese carácter, en cierto modo ritual, se completa -en el caso de las bri- 
gadas de limpieza- con una representación de un acto cotidiano, trasladado a otro escenario. El carácter ritual e incluso festivo, se hace evidente al entrar en juego una estética de pasacalles con "batucadas" y grupos de danza que desfilan a la cabeza del evento. Como mostró Low (1996), han sido muchos los estudios que se han referido a este tipo de acciones como formas de ritualización del conflicto, manifestaciones de una "ciudad contestada" en las que se invierten simbólicamente las relaciones de poder y se muestra la pugna por subvertir situaciones en las que se ven mermadas las condiciones materiales de vida y la reproducción social. Son situaciones rituales que permiten a los sujetos "intensificar y reconstruir sus vínculos" y construir identidad social (Cucó, 2004). La ritualización de la comunidad barrial se mostró en otros momentos como concentraciones contra una manifestación organizada en el barrio por España 2000 o contra la Islamofobia, frente a la puerta del Centro Cultural Islámico.

\section{Conclusiones... para seguir}

El ejercicio etnográfico está inherentemente ligado a las subjetividades, incluida la del propio investigador. Los tiempos y la relación del etnógrafo con los sujetos, en el proceso investigador, son necesariamente lentos y próximos. Conceptos teóricos como subjetividad, agencia y comunidad son, por ello, particularmente comprensibles en la práctica a través de la etnografía. De este modo, se puede aprehender cómo los miembros de una comunidad y, con ellos, el etnógrafo, construyen cotidianamente un lugar en el presente, en la memoria y en sus proyectos de futuro. El barrio puede ser ese lugar, siempre que así sea planteado por los propios sujetos desde una experiencia que no es ajena a dinámicas externas que, desde el mercado, el poder gubernamental o las instituciones oficiales, llaman la atención o actúan sobre él. Por otra parte, los sujeto pueden pugnar por contrarrestar con sus prácticas las condiciones de periferia y marginalidad y ocupar incluso un lugar central ellos o su barrio.

Las viñetas con la que hemos cerrado el último apartado parten de subjetividades que emergen en situaciones en las que se expresan emociones, deseos o intereses. Las situaciones planteadas no agotan el conjunto de las posibles, pero contribuyen a ver cómo se orientan decisiones colectivas. Por otra parte, algunas de ellas representan formas de agencia, en el sentido de construcción de capacidad de acción por vecinos sobre la realidad en la que viven y sentimiento de que pueden hacer algo contra las condiciones objetivas que enmarcan su día a día. Esos esfuerzos y expresiones pueden ser interpretados como un doble proceso de emergencias de centralización, en la medida en que algunos de esos vecinos son inmigrantes de origen extranjero que salen de cierta situación marginal para ocupar, aunque sea momentáneamente, una centralidad en la toma de decisiones y la acción colectiva. A su vez, el barrio periférico se resitúa como el centro de formas de acción colectiva que tratan de subvertir formas la injusticia espacial que aqueja el barrio y la exclusión a la que se ven sometidos los vecinos extranjeros por su situación jurídica o por su religión.

\section{Bibliografía}

Agier, M. (1995). Pour une anthropologie critique de la pauvreté (Note sur trois paradigmes culturalistes. Contribution pour le Séminaire préparatoire au Sommet Mondial pour le Développement Social (Copenhague, mars 1995).

Agier, M. (1996). Le savoirs urbanis de l'anthropologie. Enquête, 4:35-58.

Agier, M. (2000). La antropología de las identidades en las tensiones contemporáneas. Revista Colombiana de Antropología, 36:6-19.

Agier, M. (2009). Les situations élémentaires de la vie urbaine. En Esquisses d'une anthropologie de la ville. Lieux, situations, mouvements. Louvain-la-neuve: Ed. Bruylant, 55-64.

Agier, M. (2012). Penser le sujet, observer la frontière. Le décéntrement de l'anthropologie. L'Homme, 203-204(3):51-75.

Amin, A. (2002), Ethnicity and the multicultural city. Living with Diversity, Report for the Department of Transport, Local Government and the Regions and the ESRC Cities Initiative. 
Aquino Moreschi, A. (2013). La subjetividad a debate. Sociológica, 80:259-278.

Bacqué, M. H. (2011). Social Mix Policies in Paris: Discourses, Policies and Social Effects. International Journal of Urban and Regional Research, 35(2): 256-273.

Barth, F. (ed) (1976). Los grupos étnicos y sus fronteras, México, FCE.

Blassand, M. (1992). Développement local et processus identitaires. En Les Partenaires du développement face au défi du local, Cagnon, C, y Klein, J. L. Eds. Chicoutini: Université du Québec à Chicoutini, 267-295.

De la Garza, E. (2000), Subjetividad, cultura y estructura, Iztapalapa, UAM.

Caggiano, S. y Segura, R. (2013). Migración, fronteras y desplazamientos en la ciudad. Dinámicas de la alteridad urbana en Buenos Aires. Revista de Estudios Sociales, 48: 29-42.

Coleman J. S. (1988). Social capital in the creation of human capital. American Journal of Sociology, 94:95-120.

Corsín, A. (2003). On Space as a Capacity. Journal of the Royal Anthropological Institute, 9:137-153.

Chaskin, R. J. (1997). Perspectives on Neithborhood and Community: A Review of the Literature. Social Service Review, 521-547.

Cucó, J. (2004). Antropología urbana. Barcelona: Ed. Ariel.

Cucó, J. (dir) (2014). La ciudad pervertida. Miradas sobre la valencia glocal. Barcelona. Ed. Anthropos.

De Certeau, M. (1990). L'invention du quotidien. Paris: Gallimard.

Delgado, M. (coord) (2003). Carrer, festa i revolta. Els usos simbòlics de l'espai públic a Barcelona (1951-2000). Barcelona: Generalitat de Catalunya.

Delgado, M. (2007). Sociedades movedizas. Barcelona: Anagrama.

García Pilán, P. y Torres, M. À. (2013). Degradación, espectacularización y espacios del miedo. El Cabanyal. En Metamorfosis urbanas. Ciudades españolas en la dinámica global. Cucó. J. Ed. Barcelona: Ed. Icaria, 353-375.

Goffman, E. (1970). Estigma. La identidad deteriorada. Buenos Aires: Ed. Amorrortu.

Gidley, B. (2013). Landscapes of belonging, portraits of life: researching everyday multiculture in an inner city estate. Identities: Global Studies in Culture and Power, 20(4): 361-376.

Gil Araújo, S. (2009). Las periferias de la metròpolis. Políticas migratorias, género y estratificación de la población latinoamericana en España. Mélanges de la Casa de Velázquez, 39(1):57-74.

Giménez, C. (2005). Convivencia Conceptualización y sugerencias para la praxis. Puntos de Vista. Cuadernos del Observatorio de las Migraciones y de la Convivencia Intercultural de la Ciudad de Madrid, 1:7-31.

Gravano, A. (2005). El barrio en la teoria social. Buenos Aires: Ed. Espacio.

Hall, S. (2003). Introducción ¿Quién necesita la identidad?. En Cuestiones de identidad cultural. Du Gay, P. y Hall, S. Coords, Buenos Aires: Ed. Amorrortu, 13-39.

Harris, A. (2014). Conviviality, Conflict and Distanciation in Young People's Local Multicultures. Journal of Intercultural Studies, 35(6):571-87.

Henning, C. y Lieberg, M. (1996). Strong Ties or Weak Ties? Neighbourhood Networks in a New Perspective. Scandinavian Housing \& Planning Research, 13:3-26.

Joseph, I. (1993). Public Spaces and Visibility. Archives \& Behaviours, 9, 3, 403-407.

Keith, M. (2009). Urbanism and city spaces in the work of Stuart Hall. Cultural Studies, 23(4): 538548.

Lockwood, D. (1996). Civic Integration and Class formation. British Journal of Sociology, 47(3): 531-550.

Lomnitz, L. (1975). Como sobreviven los marginados, México, Siglo XXI.

López Sala, A. M. (2006). Derechos de ciudadanía y estratificación cívica en sociedades de inmigración. En Una discusión sobre la universalidad de los derechos humanos y la inmigración. Campoy, I. Ed. Madrid: Dykinson /Universidad Carlos III, 129-151.

Low, S. (1996). The anthropology of cities. Imagining and theorizing the city. Annual Review of Anthropology, 25:383-409.

Maglioni, C. y Elizalde, C. (2013). La sociabilidad barrial de las familias que padecen pobreza persistente. VII Jornadas de Jóvenes Investigadores, Instituto de Investigaciones Gino Germani, Facultad de Ciencias Sociales, Universidad de Buenos Aires, Buenos Aires.

Milliot, V. (2003). Ville fragile et paroles vives. Notes sur le rôle de l'oralite dans le contexte des banlieues-mondes. P.U.L. Litterature orale. Paroles vivantes et mouvantes, Textes reunis par 
J.B. Martin et N. Decourt, P.U.L, 123-138.

Mitchell, C. (1956). The Kalela Dance. Aspects of social relationships among urban Africans in Northern Rhodesia," Rhodes-Livingstone Papers, 27.

Moncusí, A. (2011). Nacionalización del interés, situaciones cotidianas y narrativas locales: de la frontera internacional a los límites culturales en una frontera pirenaica. Papeles del CEIC, 6(2

Morin, R. y Rochefort, M. (1998). Quartier et lien social: des pratiques individuelles à l'action collective. Lien social et Politiques, 39:103-114.

Peirano, M. (1998). When anthropology is at home: The Different Contexts of a Single Discipline. Annual Review of Anthropology, 27:105-128.

Povrzanović Frykman, M. (2015). Cosmopolitanism in situ: conjoining local and universal concerns in a Malmö neighbourhood. Identities: Global Studies in Culture and Power, DOI: 10.1080/1070289X.2015.1016525

San Román, T. (1991). La marginación como dominio conceptual. Comentarios sobre un proyecto en curso. En Antropología de los Pueblos de España. Prat, J. y otros Coords. Madrid: Ed. Akal.

Santamarina, B. (2014). La ciudad suplantada. Percepciones sobre los nuevos imaginarios (turísticos) de la ciudad de Valencia. Pasos, 12(4):707-718.

Santamarina, B. y Moncusí, A. (2013). De huertas y barracas a galaxias faraónicas. Percepciones sociales sobre la mutación de la ciudad de Valencia. Papers, 98(2): 365-391.

Semprini, A. (1994). Espaces privés, espaces publics. Privé et public comme catégories pratiques. Espaces et Sociétés, 73: 137-164.

Sewell, W. H. (2006[1992]). Una teoría de estructura. Dualidad, agencia y transformación. Arxius de Ciències Socials, 14:145-176.

Signorelli, A. (1999). Antropología urbana. Barcelona: Ed. Anthropos.

Tonnelat, S. (2010). The Sociology of Public Spaces. en Wang Hongyang, En Territorial Evolution and Planning Solution: Experiences from China and France. Savy M. and Zhai Guofang Eds. Paris: Ed. Atlantis Press.

Torres Pérez, F. (2007). Nous veïns a la ciutat. València. Valencia: Ed. Publicacions de la Universitat de València.

Torres, F., Esteban, F. O. y Moncusí, A. (2015). Crisis, convivencia multicultural y efectos de barrio. El caso de dos barrios de Valencia, Migraciones, 37:217-238.

Toubon, J.C. y Messamah, K. (1990). Centralité immigrée. Le quartier de la Goutte-d'Or. Paris: Ed. L'Harmattan.

Van Eijk, G. (2012). Good Neighbours in Bad Neighbourhoods: Narratives of Dissociation and Practices of Neighbouring in a Problem' Place. Urban Studies, 49(14):3009-26.

Van Ham, M. y Manley, D. (2012). Neighbourhood Effects Research at a Crossroads: Ten Challenges for Future Research, Iza Discussion Paper Series, 6793.

Vivant, E. (2007). L'instrumentalisation de la culture dans les politiques urbaines: un modèle d'action transposable? Espaces et Sociétés, 131(4): 49-66.

Wacquant, Ll. (2001). Parias urbanos. Buenos Aires: Ed. Manantial.

Wellman, B. (1979). The Community Question: The Intimate Networks of East Yorkers. American Journal of Sociology, 84(5):1201-31.

Wellman, B. (1999). The Network Community: An Introduction. En Networks in the Global Village. Life in Contemporary communities. Wellman, B, Ed. Boulder: Ed. Wetsview Press, 1-47.

Wellman, B. (2001). Physical place and cyberplace: the rise of personalised networking. International Journal of Urban and Regional Research, 25: 227-252.

Wellman, B. y otros (1988). Networks as personal communities. En Social Structures: A network approach. Wellman B. and Berkowitz S. Eds. Cambridge: Ed. Cambridge University Press, 130-84.

Wessendorf, S. (2013). Commonplace diversity and the 'ethos of mixing': perceptions of difference in a London neighbourhood, Identities: Global Studies in Culture and Power, 20(4):407-422.

Wimmer, A. (2004). Does ethnicity matter? Everyday group formation in three Swiss immigrant neighbourhoods. Ethnic and Ratial Studies, 27(1):1-36. 